\title{
Sperm characteristics and fertilization success of masculinized coho salmon (Oncorhynchus kisutch)
}

\author{
J.L. Fitzpatrick ${ }^{\mathrm{a}, *, 1}$, J.C. Henry ${ }^{\mathrm{b}, 2}$, N.R. Liley ${ }^{\mathrm{a}, 1}$, R.H. Devlin ${ }^{\mathrm{c}, 3}$ \\ ${ }^{a}$ Department of Zoology, The University of British Columbia, 6270 University Boulevard, Vancouver, Canada, B.C. V6T 1Z4 \\ ${ }^{\mathrm{b}}$ Target Marine Products Llp, PO Box 157 Madeira Park, Canada, B.C. VON $2 \mathrm{HO}$ \\ ${ }^{\mathrm{c}}$ Fisheries and Oceans Canada, 4160 Marine Drive, West Vancouver, Canada, B.C. V7V 1N6
}

Received 2 September 2004; received in revised form 11 February 2005; accepted 11 February 2005

\begin{abstract}
Endocrine technologies and sex modification of fish stocks are playing an increasingly important role in commercial aquaculture production. The characteristics and fertilization success of sperm from masculinized coho salmon (Oncorhynchus kisutch) were examined and compared to that of regular coho salmon sperm. Sperm from masculinized XX males was stripped, or when the efferent ducts were not developed the semen was collected from the testis, and compared with semen from normal $\mathrm{XY}$ males. Stripped masculinized genetic females exhibited similar measures of sperm velocity and sperm density as normal male coho salmon, with both of these groups differing significantly from testicular sperm from masculinized females. In commercial fertilization trials, fertilization success was not altered by the dichotomy observed between testicular and stripped milt from masculinized females. Treatment with leutenizing hormone releasing analogues had no effect on sperm motility, density, or fertility. Much of the difference in sperm characteristics can be attributed to the difference between stripped sperm and testicular sperm.
\end{abstract}

(C) 2005 Published by Elsevier B.V.

Keywords: Salmon; Sperm; Masculinized; Monosex

* Corresponding author. Department of Biology, McMaster University, 1280 Main Street West, Hamilton ON, Canada, L8S 4K1. Tel.: +1 905525 9140x23237; fax: +1 9055296225 .

E-mail address: fitzpaj1@mcmaster.ca (J.L. Fitzpatrick).

${ }^{1}$ Tel.: +1 604822 2131; fax: +1 6048222416 .

${ }^{2}$ Tel.: +1 604883 2801; fax: +1 6048832836 .

${ }^{3}$ Tel.: +1 604666 7926; fax: +1 6046663497 .

\section{Introduction}

The recent decline in worldwide fish stocks has highlighted the need for a better understanding of the environmental and physiological factors that limit the success of natural and cultured populations (Donaldson et al., 2000). The plasticity of gonadal sex development of fish has been exploited in fish culture, with producers taking advantage of various techniques to regulate sex and morphological features (Donald- 
son and Devlin, 1996; Piferrer, 2001), and monosex stocks have proven particularly useful for many species (i.e. salmonids: Donaldson and Hunter, 1982; Piferrer, 2001; carp: Gomelsky et al., 1994; Rougeot et al., 2002). Female salmon monoculture stocks eliminate precocious development of males, reduce early maturation and subsequent mortality in broodstock facilities, and reduce the number of necessary broodstock fish, while increasing the number of eggs collected from farmed populations for sale in specialty markets (Donaldson and Hunter, 1982). Monosex stocks may also provide a safeguard, in some circumstances, against potential establishment of exotic farmed fish by escape from commercial facilities (Johnson et al., 1978; Devlin and Donaldson, 1992). Collectively, these factors may enhance the value of the stock, thereby increasing the appeal of producing monoculture stocks in commercial enterprises.

Although direct feminization of salmonids is possible, cultured fish destined for the human food supply in many parts of the world may not be artificially exposed to exogenous hormones. The production of all-female salmon stocks, therefore, relies on the availability of a masculinized female broodstock. In salmonids, the genetic male (XY) normally develops testes when mature, and the genetic female (XX) develops ovaries (Devlin and Nagahama, 2002). Through the addition of exogenous androgens during early development sexual characteristics of XX females can be reversed, with gonadal and somatic phenotypic characteristics corresponding to those of normal XY males (Donaldson and Hunter, 1982). Recently, the development of Ychromosomal DNA markers has facilitated the development of monosex female stocks for some salmon species (Devlin et al., 1991, 1994; Devlin and Nagahama, 2002).

Maximizing the quality of sperm obtained in a commercial setting is of vital concern for producers. While a standard against which to measure sperm quality has not yet been determined, several authors have examined sperm density (Piironen and Hyvarinen, 1983; Aas et al., 1991), velocity (Christen et al., 1987; Aas et al., 1991; Crosson et al., 1995), milt colour (Aas et al., 1991), percentage of motile sperm (Cieresko and Dabrowski, 1994), adenosine triphosphate (ATP) concentration (Christen et al., 1987), and the composition of seminal fluids (Aas et al., 1991; Lahnsteiner et al., 1998) as evaluation criteria. Despite many studies, correlating these parameters with fertilization success has proved difficult. Sperm motility has often been used as a primary, informal determinate of sperm quality because it is relatively easy to observe. Indeed, a negative relationship between the time since sperm activation and the proportion of eggs fertilized has been demonstrated (Ginsburg, 1963; Hoysak and Liley, 2000), which suggests that the duration of motility is tied to fertilization success. Furthermore, while not ubiquitously demonstrated, several studies have shown a positive correlation between sperm motility and fertilization success in rainbow trout (Moccia and Munkittrick, 1987; Cieresko and Dabrowski, 1994; Lahnsteiner et al., 1998).

In teleosts, the masculinization procedure may have a variety of impacts on sperm characteristics and gonadal development; ranging from reductions in sperm density and motility in Betta splendens (Kirankumar and Pandian, 2002), to deformations of the testis in the Eurasian perch (Perca fluviatilis, Rougeot et al., 2002), to the development of normal gonads and sperm ducts in the northern pike (Esox lucius, Luczynski et al., 2003). In salmonids, sexual development is often disrupted in sex-reversed fish, with masculinized females generally exhibiting incomplete testicular development, incomplete sperm duct formation, and lower sperm production (Johnson et al., 1979; Geffen and Evans, 2000). While functional gonoducts have been reported in sex-reversed rainbow trout (Tsumura et al., 1991) and chinook salmon (Solar et al., 1987), these studies only provided subjective estimates of sperm characteristics. Geffen and Evans (2000) presented the first comparison of sperm from normal and masculinized trout and attributed most of the differences between testicular sperm (sperm extracted through maceration of the testes) and sperm in milt stripped from the genital pore of normal males. In the study by Geffen and Evans (2000), the masculinized trout did not exhibit functional gonoducts.

In the present investigation, approximately half of the masculinized coho exhibited complete duct formation allowing, for the first time, a direct comparison of testicular sperm with sperm in milt from masculinized coho salmon of the same (XX) 
genotype. In addition, sperm of masculinized coho salmon were compared with sperm of normal male coho salmon in an attempt to determine if sex-reversal affects sperm characteristics. Masculinized females were also treated with various leutenizing hormone releasing hormone analogues (LHRHa), in an attempt to stimulate spermiation, thereby enhancing sperm yields. Several treatments were applied, under different conditions, in order to determine an optimal treatment regime.

\section{Methods}

\subsection{Study area and species}

Domesticated coho salmon (Oncorhynchus kisutch) were masculinized using androgen treatment in the winter of $1998 / 99$ at an aquaculture facility in British Columbia, Canada. Alevins were treated by immersion for $2 \mathrm{~h}$ periods in aqueous $17 \alpha$-methyltestosterone solutions as described by Baker et al. (1988). All fish were grown to maturity in salt water, and returned to a freshwater hatchery facility upon maturation during the fall spawning season of 2001. Blood was collected with a syringe needle from the caudal peduncle of individual salmon, and $2 \mu \mathrm{l}$ of blood was lysed in $100 \mu \mathrm{l}$ of $0.01 \mathrm{~N} \mathrm{NaOH}$, followed by treatment at $95{ }^{\circ} \mathrm{C}$ for 5 min. Samples were genotyped using PCR analysis of a Y-chromosomal DNA marker (Du et al., 1993; Devlin et al., 2001) that is very closely linked to the male sex-determination locus in this species, allowing fish with $\mathrm{XX}$ and $\mathrm{XY}$ genotypes to be distinguished. Masculinized XX females were selected for analysis.

Masculinized genetic females were held in 4-m diameter $\left(13 \mathrm{~m}^{3}\right)$ tanks and normal genetic females and males were held in 9-m diameter $\left(80 \mathrm{~m}^{3}\right)$ tanks, supplied with flow-through creek water $\left(3.3-6.6{ }^{\circ} \mathrm{C}\right)$. Fish were maintained separated by sex. Fish were sampled in two separate groups, one on November 8 and the second on November 15, 2001.

\subsection{Gamete collection}

Fish were killed with a blow to the top of the head. Subsequently, the gills of ripe females were slit and bled and eggs were collected from a ventral incision made in the abdominal wall. Eggs were held in a sealed plastic container at ambient temperature (approximately $5-10{ }^{\circ} \mathrm{C}$ ) until fertilization (approximately $3-$ $5 \mathrm{~h}$ following oocyte extraction). Milt (sperm and seminal plasma) was collected from males by gentle abdominal massage following emptying of the urinary bladder. If sperm ducts were not fully formed or not functional, the testes were manually removed and cut into pieces, without maceration, with a scalpel and free flowing milt was gently squeezed from the testes. Milt was stored in sealed, oxygenated plastic bags and immediately placed on paper towel over ice (Billard, 1981). Care was taken to avoid contamination of the gametes with mucus, urine and blood and testes fragments.

\subsection{Analysis of sperm}

Sperm density was recorded using a spermatocrit index, which has a strong correlation with the number of sperm cells per unit volume (as counted with the aid of a hemocytometer) in trout and halibut (Bouck and Jacobson, 1976; Tvedt et al., 2001). Two capillary tubes were filled with milt and centrifuged in a microhematocrit centrifuge for $10 \mathrm{~min}$. Sperm cells pack down in the capillary tube forming an opaque layer while seminal fluid remains in a clear layer in the top of the tube. The percentage of packed sperm was measured using a hematocrit reader. The average of the two capillary tube values was recorded as the spermatocrit value.

Motility was assessed using a procedure similar to that of Liley et al. (2002). Briefly, $0.5 \mu 1$ milt was activated by $5 \mathrm{ml}$ well water in a $10 \mathrm{ml}$ glass beaker. Activated milt was quickly (5-7 s) placed on a prefocused and positioned 1-mm welled slide, with a cover slip over half of the well. Motility was recorded under a compound Leitz Wetzlar light microscope $(\times 100$ magnification $)$, fitted with a Cohu Solid State video camera (model 4815, Cohu, San Diego, California). The procedure was repeated twice for each sample and recorded using a Sanyo video recorder (SRT-500, Sanyo Electric, Japan). Video recordings were started at the time of sperm activation. The proportion of sperm motile $10 \mathrm{~s}$ after activation was estimated from video recordings on a $0-5$ scale. Only sperm exhibiting forward movement 
were recorded as motile; vibrating sperm were considered nonmotile. The $0-5$ scale was divided into percentage of motile cells: $5=>95 \%$ motile; $4=75-94 \%$ motile; $3=30-74 \%$ motile; $2=10-29 \%$ motile; $1=<10 \%$ motile; $0=$ no activity (Defraipoint and Sorensen, 1993; Liley et al., 2002). Sperm velocity was analyzed by projecting the recorded image onto a large screen $(\times 4800)$ and tracing the swimming speed of 10 individual sperm cells for each fish at 10, 20 and $30 \mathrm{~s}$ post activation by tracking the movement of cells every second frame for $1 \mathrm{~s}(30$ frames $/ \mathrm{s})$. A $0.01 \mathrm{~mm}$ scale was projected onto the screen used to trace sperm cells, under the same magnification, and absolute swimming speeds were calculated using this size standard (velocity= distance/time). (Note: testicular fragments may rarely have been included in testicular milt samples. These relatively large, non-spherical fragments could be easily distinguished from sperm cells and were ignored when examining the percentage of motile cells and sperm velocity.)

In commercial fertilization trials, $3-5 \mathrm{ml}$ of milt was poured over 1-1.5 1 of eggs and mixed by hand for $5 \mathrm{~s}$. One liter of water was added to activate the sperm, and the mixture was mixed further for another $10 \mathrm{~s}$ and then left to sit for 3-5 min. Following fertilization, a sub-sample of eggs were placed in incubation trays $12 \mathrm{~cm}$ in diameter, which were then placed in Heath trays incubators with a constant 12-1/ min flow of well water.

Eggs were examined the day after fertilization and the eggs that had turned opaque were removed and were assumed to be damaged as a result of mechanical stress of gamete handling and were not included in the calculation of the fertilization success. The eggs were not disturbed thereafter. Fertilization rate was determined by examining the number of eyed eggs present 30 days post-fertilization. Variable volumes of sperm were used in fertilization trials, as this study was meant to test sperm fertility characteristics under commercial production conditions.

Fertilization values are based upon the first (November 8) group sampled. During the incubation period the eggs taken from fish sampled in the second group suffered heavy losses due to a fungal attack and were therefore not included in the analysis.

\subsection{Treatment with luteinizing hormone releasing factors (LHRHa)}

Fish were anesthetized with clove oil before they were injected. Hormones were dissolved at a concentration of $150 \mu \mathrm{g} / \mathrm{ml}$. Ten adult maturing fish were injected with a single dose of $150 \mu \mathrm{g}$ [D-Arg ${ }^{6}$, Des, $\mathrm{Gly}^{10}$ ] GnRH ethylamide (Arg), a salmon derived analogue, 10 fish were first given a priming dose of 30 $\mu \mathrm{g}$, and 2 days later a further $120 \mu \mathrm{g}$ D-Arg-6 treatment (Arg P), 10 fish were injected with a 30 $\mu \mathrm{g}$ primer followed by a $120 \mu \mathrm{g}$ [D-Ala ${ }^{6}, \mathrm{Des}, \mathrm{Gly}^{10}$ ] LHRH ethylamide (Ala P), a mammalian derived analogue, and finally 10 fish were implanted with Ovaplant (D-Arg ${ }^{6}$, Des, Gly ${ }^{10} \mathrm{GnRH}$ ethylamide; Syndel Laboratories, Vancouver, BC), a commercially available analogue $(150 \mu \mathrm{g})$. With the exception of the Ovaplant implant all other treatments were dissolved in a saline solution prior to injection. Fish were injected intraperitonially at the base of the pelvic fin using a $1 \mathrm{ml}$ syringe fixed with a 16 -gauge needle. All injections were done 10 days before sampling. The fish were then isolated in a separate tank for 10 days. Ten randomly assigned masculinized fish that did not receive treatment were added to the tank to serve as a control. Previously implanted PIT (Passive Integrated Transponder; AVID Canada) tags were recorded at the time of injections to identify individual fish. These groups were compared to normal genetic males taken from the breeding stock.

\subsection{Statistical analysis}

One-way analysis of variance (ANOVA) followed by pair-wise comparisons between groups, using a Tukey test, were used to test for differences among three or more groups. Differences in sperm duct formation between masculinized fish (LHRHa and non-treated control fish) were examined using a log likelihood $G$ test. When the assumption of normality was violated, comparisons between means were performed using a Mann-Whitney test (two groups), or a Kruskal-Wallis test (three or more groups). Multivariate correlation analysis was used to determine if correlations existed between variables and was tested using a Spearman's Rho test. Analysis was completed using SigmaStat Version 2.03. The level of significance was set at $p<0.05$. 


\section{Results}

Three characteristics of sperm quantity and quality were examined in this study: sperm density, motility and fertilization success. Normal males tended to have greater volumes of sperm available when being stripped, while masculinized coho expressed smaller volumes of milt or were incapable of expressing milt due to incomplete formation of sperm ducts. In $46 \%$ of the masculinized females, sperm was stripped manually (i.e. sperm duct formation was complete), while the remaining $54 \%$ of the samples were obtained directly from the testes.

Sperm density, velocity, and fertilization success were not altered by any of the LHRHa hormone treatments applied (Fig. 1). There were no differences
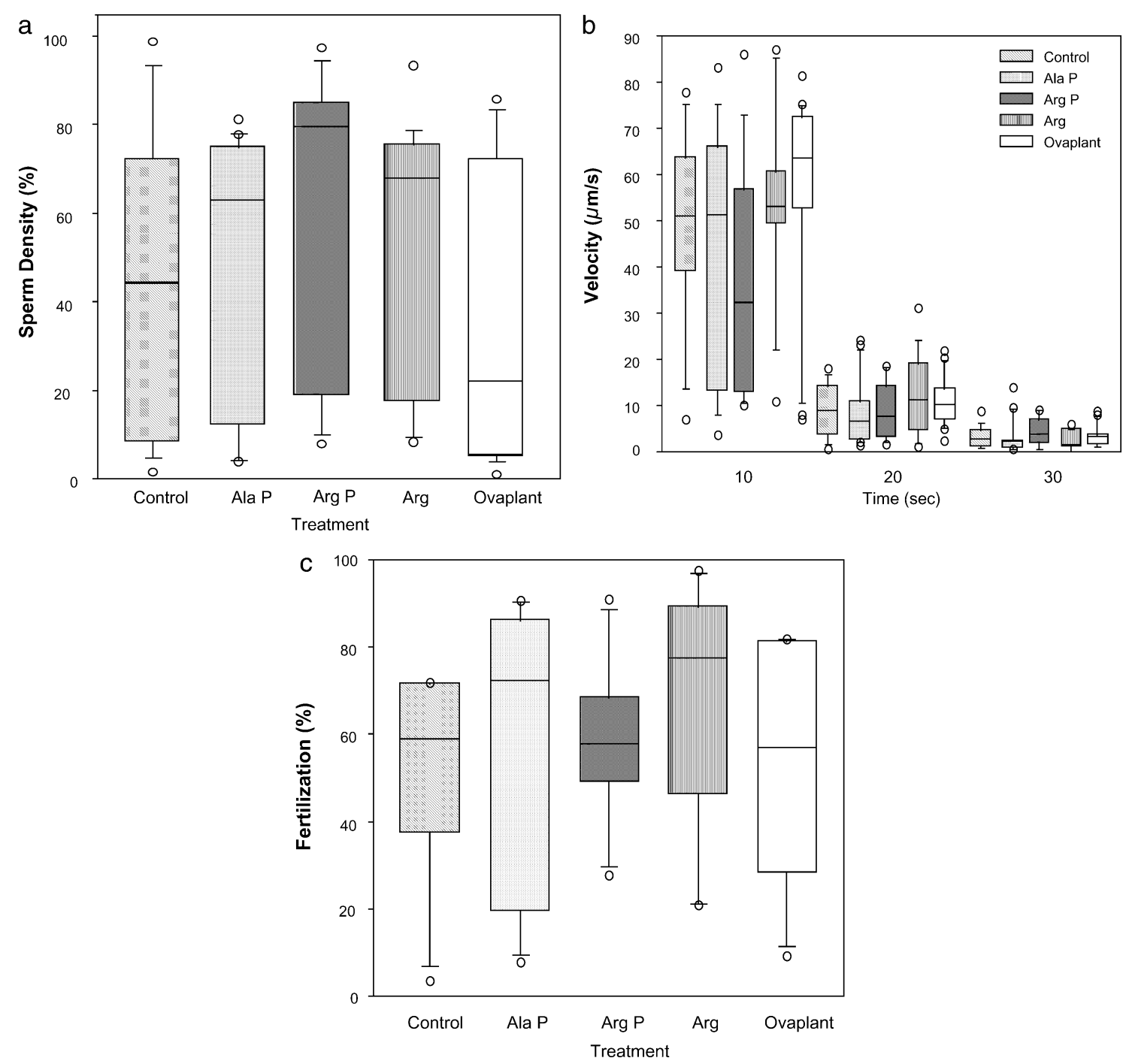

Fig. 1. (a) Sperm density of milt from masculinized females treated with LHRH analogues. (b) Sperm velocity 10,20 and $30 \mathrm{~s}$ post activation of milt from masculinized females treated with various LHRH analogues. Similar mean sperm velocities $(p>0.05)$, as determined by a Tukey test, are identified by the same superscript letter. (c) Proportion of eggs fertilized in clutches of eggs inseminated by milt from masculinized females treated with various LHRH analogues. Box plots show 10th, 25th, 50th (median), 75th, and 90th percentiles as horizontal lines, plus all data points outside this range. Control: untreated masculinized females; Ala P, Arg P, Arg, and Ova: LHRHa treatments described in text. 
in the prevalence of sperm duct formation between LHRHa treatment groups $(p=0.16)$ and, when all LHRHa treatment groups were pooled, there were no differences in sperm duct formation between LHRHa treated fish and the non-treated control fish $(p=0.79)$. Therefore, further analysis focused on the differences between stripped and testicular sperm from masculinized females, grouping the LHRHa treated groups and the non-treated control group together.

The mean sperm density of milt stripped directly from masculinized females did not differ from that of normal males. However, sperm density of milt extracted directly from the testes of masculinized females with incomplete gonoducts was significantly higher than both types of stripped milt (Fig. 2, $p<0.001$ ).

The swimming velocity of sperm from both stripped masculinized females and stripped normal males did not differ but were higher at $10 \mathrm{~s}$ post activation than that of sperm from testicular milt (Fig. $3, p<0.001)$. Velocity declined rapidly and at both 20 and $30 \mathrm{~s}$ post activation there were no differences between any of the groups. The proportion of sperm motile $10 \mathrm{~s}$ after activation was significantly higher in milt stripped from normal males and masculinized

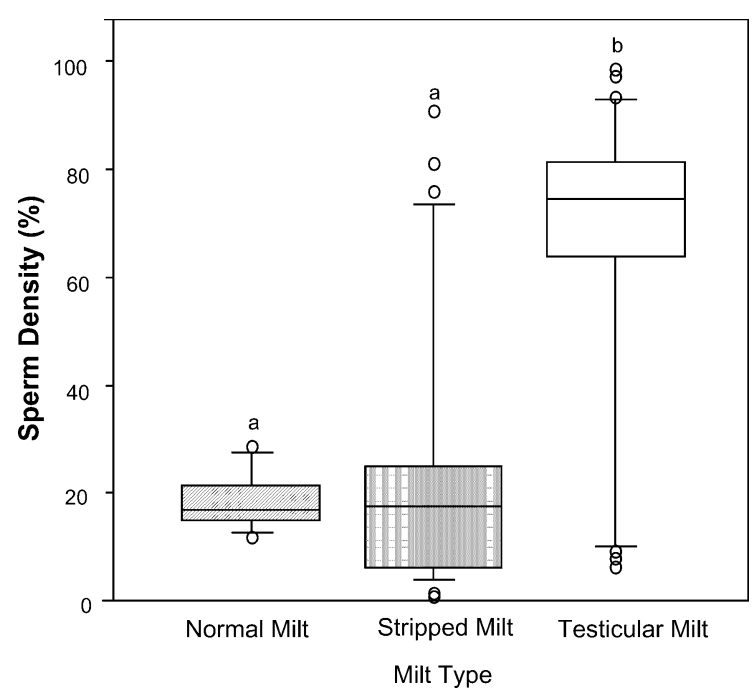

Fig. 2. Sperm density of milt from normal males and stripped and testicular milt from masculinized females. Similar mean sperm densities $(p>0.05)$, as determined by a Tukey test, are identified by the same superscript letter. Box plots show 10th, 25th, 50th (median), 75th, and 90th percentiles as horizontal lines, plus all data points outside this range.

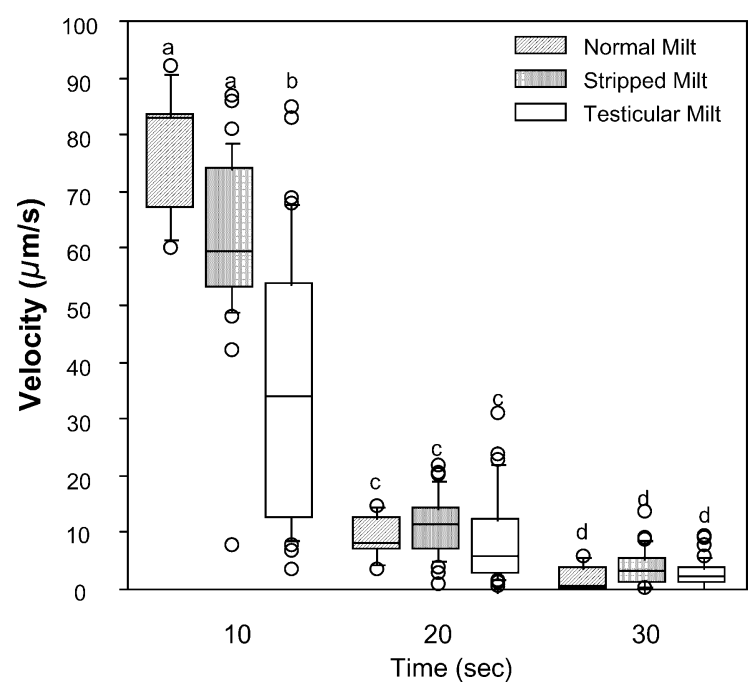

Fig. 3. Sperm velocity of milt from normal males and stripped milt and testicular milt from masculinized females 10, 20 and $30 \mathrm{~s}$ post activation. Similar mean sperm velocities $(p>0.05)$, as determined by a Tukey test, are identified by the same superscript letter. Box plots show 10th, 25th, 50th (median), 75th, and 90th percentiles as horizontal lines, plus all data points outside this range.

females, than from testicular milt from masculinized females (Fig. 4, $p<0.001$ ).

The fertilization success of masculinized females did not differ between stripped (mean $\pm \mathrm{SE}$,

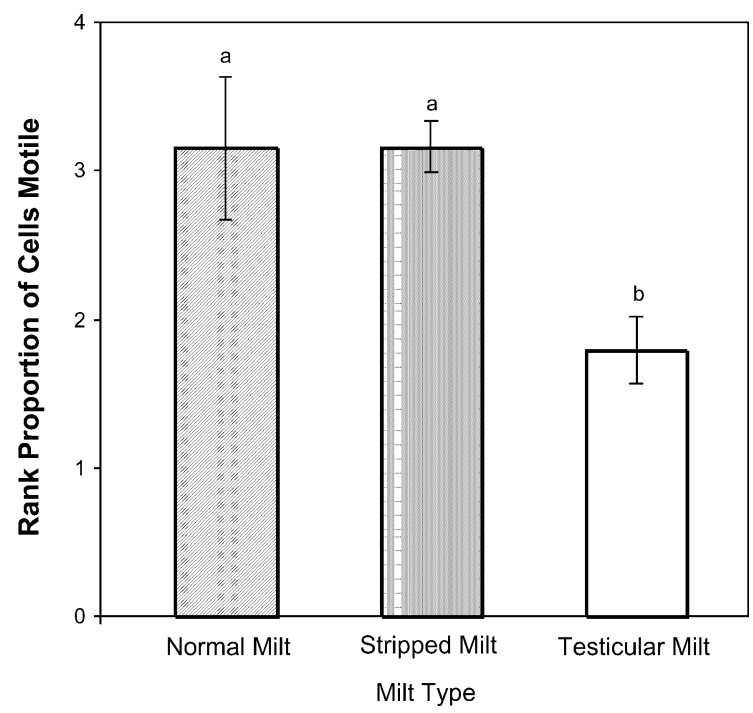

Fig. 4. Proportion of sperm motile (mean \pm SE) in stripped milt and testicular milt from masculinized females $10 \mathrm{~s}$ after activation. Similar mean proportions of motile sperm $(p>0.05)$, as determined by a Tukey test, are identified by the same superscript letter. 
$57.4 \pm 6.7, n=16)$ and testicular milt $(57.2 \pm 6.7$, $n=20, p=0.984)$ under commercial conditions. Multivariate correlation analysis did not detect any correlation between fertilization success and the sperm characteristics examined.

\section{Discussion}

Salmon sperm activity is short lived, with motility lasting from 20-40 s (Ginsburg, 1963; Crosson et al., 1995). Motility of sperm stripped from masculinized females were similar to sperm stripped from normal males, while testicular milt differed from both types of stripped milt, suggesting that regular sperm development occurs in masculinized females when sperm duct formation is complete. Following spermatogenesis, sperm undergo modifications, with an increase in $\mathrm{pH}$ in the seminal plasma of the sperm duct allowing sperm to become motile upon release into a hypoosmotic solution (Miura et al., 1992; Kobayashi et al., 2004). Thus, maturation of sperm cells occurring during the passage along the sperm duct has not occurred in testicular milt. The velocity of both testicular and stripped milt from masculinized coho declined sharply over a $30 \mathrm{~s}$ period, and higher sperm densities were typical of sperm extracted directly from the testes.

The similarities between swimming velocities of sperm stripped from masculinized females and normal males suggest that the masculinization procedure does not influence sperm development and maturation. These similarities however, are dependent on complete development of sperm ducts in masculinized females. When investigating sperm characteristics of masculinized rainbow trout, Geffen and Evans (2000) attributed the reduction in sperm quality in masculinized females to the differences between testicular and stripped milt. This also appears to be the case for masculinized coho.

In their study of masculinized rainbow trout females, Geffen and Evans (2000) dealt solely with testicular sperm due to the fact that a high proportion of sex-reversed rainbow trout exhibited incomplete sperm duct formation forcing manual extraction of gonads in order to obtain milt (Geffen and Evans, 2000; Johnson et al., 1979). In the present study $46 \%$ of the masculinized females exhibited complete sperm duct formation, allowing the first comparisons between testicular and stripped sperm from within the $\mathrm{XX}$ genotype, and comparison with normal $\mathrm{XY}$ males.

In most cases, sperm that was obtained directly from the testes was motile upon activation with water. The proportion of motile sperm, however, was lower in testicular sperm when compared to sperm in milt stripped from the fish. Testicular sperm is likely to contain more immature cells (Geffen and Evans, 2000) or have additional cellular material present when extracting milt directly from the testes. As testicular fragments are easily distinguishable from sperm cells, these fragments are not likely to influence measures of sperm swimming velocity or proportion of cells motile. Testicular fragments, however, are likely to inflate measures of sperm density and may be responsible for the increase in sperm density in testicular samples observed in this study. In order to quantify the effect of testicular fragments on sperm density measures a microscopical or histological characterization of testicular milt is required.

Nonmotile sperm may influence fertilization success by blocking sperm access to the micropyle. Levanduski and Cloud (1988) reported that fertilization success was reduced when the concentration of immotile sperm exceeded $90 \%$ of total sperm. The average proportion of motile testicular sperm was greater than $10 \%$ motile sperm in the present experiments, suggesting that immotile sperm obtained from the testes did not play a major role in determining fertilization success in this study.

Several studies have demonstrated the use of LHRH and its analogues to stimulate sexual development, maximizing gamete yields, in salmonids (Olsen and Liley, 1993; McLean et al., 1991; Crim et al., 1983; Ravaglia et al., 1997; King and Young, 2001; Mylonas et al., 1997). We therefore predicted an increase in gamete yield and, if sperm motility is influenced by reproductive hormones as suggested by Miura et al. (1992), an increase in the sperm motility parameters studied. Contrary to these hypotheses, sperm motility characteristics and fertilization success were not altered by LHRHa treatments. Olsen and Liley (1993) reported a rapid increase in spermiation following exogenous hormone treatments. In the present study, sperm was collected 10 days after 
treatment, suggesting the effects of the treatments may not have been observed due to the delay between administering the hormone and measuring sperm characteristics and fertility. However, surprisingly, treatment with slow-release Ovaplant implants also did not alter sperm characteristics, perhaps due to the overriding influence of the differences between stripped and testicular sperm masking any potential influence.

Despite observed differences in sperm motility, sperm density and rank proportion of active sperm in testicular and stripped sperm, there was no difference in fertility between treatments. While the course nature of our fertilization trials (see below) may have failed to detect a difference between treatments, a relationship between sperm characteristics and fertilization success has not been clearly demonstrated in other studies as well (see Hoysak and Liley, 2000). In keeping with the findings of Geffen and Evans (2000) the present study did not detect a relationship between sperm density and fertilization success. The positive correlation between sperm motility and fertility observed in rainbow trout (Moccia and Munkittrick, 1987; Lahnsteiner et al., 1998; Cieresko and Dabrowski, 1994) has not been confirmed in Atlantic salmon (Aas et al., 1991), sockeye salmon (Hoysak and Liley, 2000), Atlantic cod (Trippel and Neilson, 1992), nor in the present study. In the present experiment, fertilization trials performed during the same spawning season, under similar conditions, normal males exhibited an average fertilization success of $82.9 \%(n=133$, J.C. Henry, unpublished data). Masculinized females, therefore, showed reduced fertility when compared to their normal counterparts, with an overall average fertilization success of $57.4 \%$. This experiment, however, may not have been robust enough to detect differences between the fertilization capacity of testicular and stripped sperm of masculinized females due to the amount of sperm used in fertilizations under these commercial conditions.

It is clear that the variation in the sperm density, velocity and fertilization success observed in the masculinized fish poses greater uncertainty in production that those of normal fish. Geffen and Evans (2000) pointed out the cost in terms of fertilization success when using sex-reversed fish. This added cost must be taken into account when evaluating the usefulness of sex-reversed stocks (Geffen and Evans, 2000), but for coho salmon the economic (reduction of precocious maturation, reduction in broodstock costs-Donaldson and Hunter, 1982) and ecological (exotic species containment when rearing outside of Pacific waters - Johnson et al., 1978) benefits may out weigh decreased fertilization success.

In conclusion, this study describes, for the first time, sperm characteristics of masculinized female coho salmon. Sperm characteristics were similar in milt collected from normal males and from stripped masculinized females. However, while the density of sperm collected from the testes of masculinized fish in which the development of the genital ducts was incomplete was higher, a lower proportion of sperm was motile following activation, and motility declined more rapidly. On the other hand the fertility of testicular sperm was similar to that of sperm in stripped milt in commercial fertilization trials. Testicular sperm from masculinized females was different from sperm collected from stripped masculinized females and normal males in all measured traits except for fertilization success. Following masculinization, sperm appear to develop normally provided sperm duct formation is complete. However, we currently do not know whether other differences such as fertilization ability between stripped and testicular sperm may be more apparent under non-commercial conditions (i.e. more dilute sperm concentrations), nor whether total sperm volume differs between masculinized and normal coho salmon. Notwithstanding these difficulties, the use of all-female populations of coho salmon has proven to be a significant benefit for commercial production of this species.

\section{Acknowledgements}

We are extremely grateful to Joyce Francis and the hatchery staff for their invaluable assistance in all aspects of this study. We thank Dionne Sakhrani for performing genetic sex-determination tests identifying masculinized females. The authors are also very grateful to three anonymous reviewers for helpful comments on the manuscript. The Fisheries and Oceans Canada's Aquaculture Collaborative Research and Development Program to R.H.D. and a grant from 
the National Science and Engineering Research Council of Canada to N.R.L supported this study.

\section{References}

Aas, G.H., Refstie, T., Gjerde, B., 1991. Evaluation of milt quality of Atlantic salmon. Aquaculture 95, 125-132.

Baker, I.J., Solar, I.I., Donaldson, E.M., 1988. Masculinization of Chinook salmon Onchorynchus tshawytscha by immersion treatments using 17-alpha methyltestosterone around the time of hatching. Aquaculture 72, 359-368.

Billard, R., 1981. Short-term preservation of sperm under oxygen atmosphere in rainbow trout (Salmo gairdneri). Aquaculture 23, 287-293.

Bouck, G.R., Jacobson, J., 1976. Estimation of salmonid sperm concentration by microhematocrit technique. Transactions of the American Fisheries Society 105, 534-535.

Christen, R., Gatti, J., Billard, R., 1987. Trout sperm motility: the transient movement of trout sperm is related to changes in the concentration of ATP following the activation of the flagellar movement. European Journal of Biochemistry 166, $667-671$.

Cieresko, A., Dabrowski, K., 1994. Relationship between biochemical constituents of fish semen and fertility: the effect of short-term storage. Fish Physiology and Biochemistry $12,357-367$.

Crim, L.W., Sutterlin, A.M., Evans, D.M., Weil, C., 1983. Accelerated ovulation by pelleted LHRH analogue treatment of spring-spawning rainbow trout (Salmo gairdneri) held at low temperature. Aquaculture 35, 299-307.

Crosson, M., Cosson, J., Andre, F., Billard, R., 1995. cAMP/ATP relationship in the activation of trout sperm motility: their interaction in membrane-deprived models and in live spermatozoa. Cell Motility and the Cytoskeleton 31, 159-176.

Defraipoint, M., Sorensen, P.W., 1993. Exposure to the pheromone $17 \alpha, 20 \beta$-dihydroxy-4-pregnen-3-one enhances the behavioural spawning success, sperm production and sperm motility of male goldfish. Animal Behaviour 46, 245-256.

Devlin, R.H., Donaldson, E.M., 1992. Containment of genetically altered fish with emphasis on salmonids. In: Hew, Choy, Fletcher, Garth (Eds.), Transgenic Fish. World Scientific Pub. Co., Singapore.

Devlin, R.H., Nagahama, Y., 2002. Sex determination and sex differentiation in fish: an overview of genetic, physiological, and environmental influences. Aquaculture 208, 191-364.

Devlin, R.H., McNeil, B.K., Groves, T.D., Donaldson, E.M., 1991. Isolation of a Y-chromosomal DNA probe capable of determining genetic sex in chinook salmon Oncorhynchus tshawytscha. Canadian Journal of Fisheries and Aquatic Sciences 48, 1606-1612.

Devlin, R.H., McNeil, B.K., Solar, I.I., Donaldson, E.M., 1994. A rapid PCR-based test for Y-chromosomal DNA allows simple production of all-female strains of chinook salmon. Aquaculture $128,211-220$.
Devlin, R.H., Biagi, C.A., Smailus, D.E., 2001. Genetic mapping of Y-chromosomal DNA markers in Pacific salmon. Genetica 111, $43-58$.

Donaldson, E.M., Devlin, R.H., 1996. Uses of biotechnology to enhance production. In: Pennell, W., Barton, B. (Eds.), Principles of Salmonid Culture. Developments in Aquaculture and Fisheries Science, vol. 29. Elsevier Publishers, pp. 969-1020.

Donaldson, E.M., Hunter, G.A., 1982. Sex control in fish with particular reference to salmonids. Canadian Journal of Fisheries and Aquatic Sciences 39, 99-110.

Donaldson, E., Solar, I.I., Harvey, B., 2000. Induced ovulation and spermiation, and factors influencing gamete quality of fishes. In: Tiersch, T.R., Mazik, P.M. (Eds.), Cryopreservation in Aquatic Species. World Aquaculture Society, Baton Rouge, Louisiana, pp. $13-19$.

Du, S.J., Devlin, R.H., Hew, C.L., 1993. Genomic structure of growth hormone genes in chinook salmon (Oncorhynchus tshawytscha) - presence of 2 functional genes, GH-I and GHII, and a male specific pseudogene GH-PSI. DNA Cell Biology $12,739-751$

Geffen, A.J., Evans, J.P., 2000. Sperm traits and fertilization success of male and sex-reversed female rainbow trout (Oncorhynchus mykiss). Aquaculture 182, 61-72.

Ginsburg, A., 1963. Sperm-egg association and its relationship to the activation of the egg in salmonid fishes. Journal of Embryology and Experimental Morphology 11, 13-33.

Gomelsky, B.I., Cherfas, N.B., Peretz, Y., Ben-Dom, N., Hulata, G., 1994. Hormonal sex inversion in the common carp (Cyprinus carpio L.). Aquaculture 126, 265-270.

Hoysak, D.J., Liley, N.R., 2000. Fertilization dynamics in sockeye salmon and a comparison of sperm from alternative male phenotypes. Journal of Fish Biology 58, 1286-1300.

Johnson, R., Simpson, T.H., Walker, A.F., 1978. Sex reversal in salmonid culture. Aquaculture 13, 115-134.

Johnson, R., Simpson, T.H., Youngson, A.F., Whitehead, C., 1979. Sex reversal in salmonid culture: Part II. The progeny of sexreversed rainbow trout. Aquaculture 18, 13-19.

King, H.R., Young, G., 2001. Milt production by non-spermiating male Atlantic salmon (Salmon salar) after injection of a commercial gonadotropin releasing hormone analog preparation, $17 \alpha$-hydroxyprogesterone or $17 \alpha, 20 \beta$-dihydroxy-4-pregnen-3one, alone or in combination. Aquaculture 193, 179-195.

Kirankumar, S., Pandian, T.J., 2002. Effect on growth and reproduction of hormone immersed and masculinized fighting fish Betta splendens. Journal of Experimental Zoology 293, 606-616.

Kobayashi, T., Fushiki, S., Ueno, K., 2004. Improvement of sperm motility of sex-reversed male rainbow trout, Oncorhynchus mykiss, by incubation in high-pH artificial seminal plasma. Environmental Biology of Fishes 69, 419-425.

Lahnsteiner, F., Berger, B., Weismann, T., Patzner, R.A., 1998. Determination of semen quality of rainbow trout, Oncorhynchus mykiss, by sperm motility, seminal plasma parameters, and spermatozoal metabolism. Aquaculture 163, 163-181.

Levanduski, M.J., Cloud, J.G., 1988. Rainbow trout (Salmo gairdneri) semen: effect of non-motile sperm of fertility. Aquaculture 75, 171-179. 
Liley, N.R., Tamkee, P., Tsai, R., Hoysak, D.J., 2002. Fertilization dynamics in rainbow trout (Oncorhynchus mykiss): effect of male age, social experience, and sperm concentration and motility on in vitro fertilization. Canadian Journal of Fisheries and Aquatic Sciences 59, 144-152.

Luczynski, M.J., Demska-Zakes, K., Dabrowski, K., Luczynski, M., 2003. Masculinization of gynogenetic northern pike juveniles using 17 alpha-methyltestosterone. North American Journal of Aquaculture 65, 255-259.

McLean, E., Parker, D.B., Warby, C.M., Sherwood, N.M., Donaldson, E.M., 1991. Gonadotropin release following oral delivery of luteinizing hormone-releasing hormone and its superactive analogue $\left(\right.$ des- $\left.^{-G l y^{10}}{ }^{1 D-A l a}{ }^{6}\right]$ LHRH ethylamide) to $17 \beta$-oestradiol-primed coho salmon, Oncorhynchus kisutch (Walbaum). Journal of Fish Biology 38, 851-858.

Miura, T., Yamauchi, K., Takahashi, H., Nagahama, Y., 1992. The role of hormones in the acquisition of sperm motility in salmonid fishes. The Journal of Experimental Zoology 261, $359-363$.

Moccia, R.D., Munkittrick, K.R., 1987. Relationship between the fertilization of rainbow trout (Salmo gairdneri) eggs and the motility of spermatozoa. Theriogenology 27, 679-688.

Mylonas, C.C., Gissis, A., Magnus, Y., Zohar, Y., 1997. Hormonal changes in male white bass (Morone chrysops) and evaluation of milt quality after treatment with a sustained-release GnRHa delivery system. Aquaculture 153, 301-313.

Olsen, K.H., Liley, N.R., 1993. The significance of olfaction and social cues in milt availability, sexual hormone status, and spawning behaviour of male rainbow trout (Oncorhynchus mykiss). General and Comparative Endocrinology 89, 107-118.
Piferrer, F., 2001. Endocrine sex control strategies for the feminization of teleost fish. Aquaculture 197, 229-281.

Piironen, J., Hyvarinen, H., 1983. Composition of the milt of some teleost fishes. Journal of Fish Biology 22, 351-361.

Ravaglia, M.A., Lo Nostro, F.L., Maggese, M.C., Guerrero, G.A., Somoza, G.M., 1997. Characterizations of molecular variants of GnRH, induction of spermiation and sex reversal using salmon GnRH-A and domperidone in the progynous diandric fish, Synbranchus marmoratus Bloch, (Teleostei, Synbranchidae). Fish Physiology and Biochemisty 16, 425-436.

Rougeot, C., Jacobs, B., Kestemont, P., Melard, C., 2002. Sex control and sex determinism study in Eurasian perch, Perca fluviatilis, by use of hormonally sex-reversed male breeders. Aquaculture 211, 81-89.

Solar, I.I., Baker, I.J., Donaldson, E.M., 1987. Experimental use of female sperm in the production of monosex females stocks of Chinook salmon Oncorhynchus tshawytscha at commercial fish farms. Canadian Technical Report of Fisheries and Aquatic Sciences 1552, 1-14.

Trippel, E.A., Neilson, J.D., 1992. Fertility and sperm quality of virgin and repeat-spawning Atlantic cod (Gadus morhua) and associated hatching success. Canadian Journal of Fisheries and Aquatic Sciences 49, 2118-2127.

Tsumura, K., Blann, V.E., Lamont, C.A., 1991. Progeny test of masculinized female rainbow trout having functional gonoducts. Progressive Fish-Culturist 53, 45-47.

Tvedt, H.B., Benfey, T.J., Martin-Robichaud, D.J., Power, J., 2001. The relationship between sperm density, spermatocrit, sperm motility and fertilization success in Atlantic halibut Hippoglossus hippoglossus. Aquaculture 194, 191-200. 